\title{
CHARACTERISATION OF MIXED BEACH SEDIMENT
}

\author{
Kaiming She ${ }^{1}$ Xiao Wei $\mathrm{Yu}^{1}$ and Ian Thomas ${ }^{2}$
}

\begin{abstract}
This paper presents a field study of a mixed sand-gavel beach which is subjected to all-year round maintenance activities including an annual recharge and recycling and/or re-profiling following storm events. Over one year period, sediment samples are collected weekly for the first month immediately after the annual recharge and then monthly afterwards. Special collections are also made before and after major storm events. The primary focus is on how the sediment characteristics varies in space and over time. In addition, the impact of the beach maintenance on the sediment sorting process is also investigated.
\end{abstract}

Keywords: Mixed beach; bi-modal distribution; sediment sorting; sediment transport

\section{INTRODUCTION}

Under the action of waves and the influence of the tide, a mixed beach undergoes a continuous profile evolution due to sediment movement in both cross-shore and alongshore direction. As the sediment is moved in the cross-shore direction, sediment particles are sorted and deposited on the beach in terms of their sizes. Sediment sorting is a continuous and dynamic process leading to highly varied sediment size distribution across the beach and over time. There are locations on the beach where the composition of the sediment is almost entirely of gravel whilst other parts of the beach can have very high sand content. The swash zone is the most active part of the beach and the surface sediment can be seen to respond to individual waves in a wave train (Powell, 1990). This results in a surface layer that is highly unstable with lateral changes occurring within a few metres and pronounced temporal changes occurring over as little as one tidal event.

Sediment sorting is a significant phenomenon on all mixed beaches. If left to take its own course, the sorting process tends to create the most efficient system for absorbing the incident wave energy thus providing an effective means of sea defence and coastal protection. A beach of coarse sediment (gravel) is capable of dissipating in excess of $90 \%$ of all incident wave energy (Powell, 1990). However sediment sorting on a disturbed beach can be interrupted due to maintenance activities such as annual recharge, recycling and re-profiling. This paper looks at the sediment characteristics of the Pevensey beach in the UK over the cycle between two annual recharges. The objectives of the study are as follows:

- To review and develop appropriate quantitative methods of characterising the sediment composition of a mixed beach;

- To examine spatial variation of the sediment characteristics in the cross-shore direction;

- To examine the changes in sediment characteristics over the weeks following the annual recharge;

- To look at the changes in sediment characteristics over the full cycle of sediment recharge;

- To investigate the influence of minor maintenance activities (recycling / re-profiling) on the sediment sorting.

\section{SCHEME OF WORK AND METHOD OF ANALYSIS}

\section{The site of study}

The location of the site is shown in Figure 1. The section of the beach covers a $600 \mathrm{~m}$ stretch immediately downcoast (northeast) of the Sovereign Harbour approach channel. The breakwaters protecting the channel inadvertently cut off all the sediment supply from the upcoast of the harbour entrance. The complete cut-off means that there is a sediment supply problem for PCDL (Pevensey Coastal Defence Ltd) who is responsible for the maintenance of the frontage but it also offers a unique opportunity to study the sediment transport processes of a maintained mixed beach. It should be possible to estimate the sediment transport rate by means of combined beach surveys and sediment sampling although this paper only deals with sediment characteristics.

Before the major recharge work in 2001, the frontage had timber groynes but these were mostly removed with only small sections remaining. The full groynes in front of Martello Tower are just timber piles with the original timber planks all removed. As a result, the frontage is effectively an open beach, an ideal site for studying the sediment transport rate. There is a Channel Coastal Observatory wave buoy $10 \mathrm{~km}$ offshore of the Sovereign Harbour, providing continuous wave data throughout the year. There is also a tidal gauge at Newhaven, about $20 \mathrm{~km}$ from the site of investigation and $30 \mathrm{~min}$

\footnotetext{
${ }^{1}$ Schhol of Environment and Technology, University of Brighton, Lewes Road, Brighton, East Sussex BN2 4GJ, UK

${ }^{2}$ Pevensey Coastal Defence Ltd, Environment Agency Depot, Coast Road, East Sussex BN24 6ND, UK
} 
time lag, making it possible to accurately estimate the local tidal condition. The maximum tidal range is about $6 \mathrm{~m}$.

The Pevensey Bay sea defences have historically been managed by the Environment Agency Southern Region. Prior to the start of the PCDL contract, the Pevensey Bay sea defences consisted of a mixed beach extending for $9 \mathrm{~km}$ between the Sovereign Harbour in Eastbourne, and Bexhill. As part of the contractual agreement, PCDL is required to maintain a $30 \mathrm{~m}$ beach crest over the whole of Pevensey frontage. As such, annual replenishment takes place during the summer and top-ups may also be carried out during the winter months when large losses occur. Local recycling and re-profiling may also take place to maintain the beach to the required standard of defence.

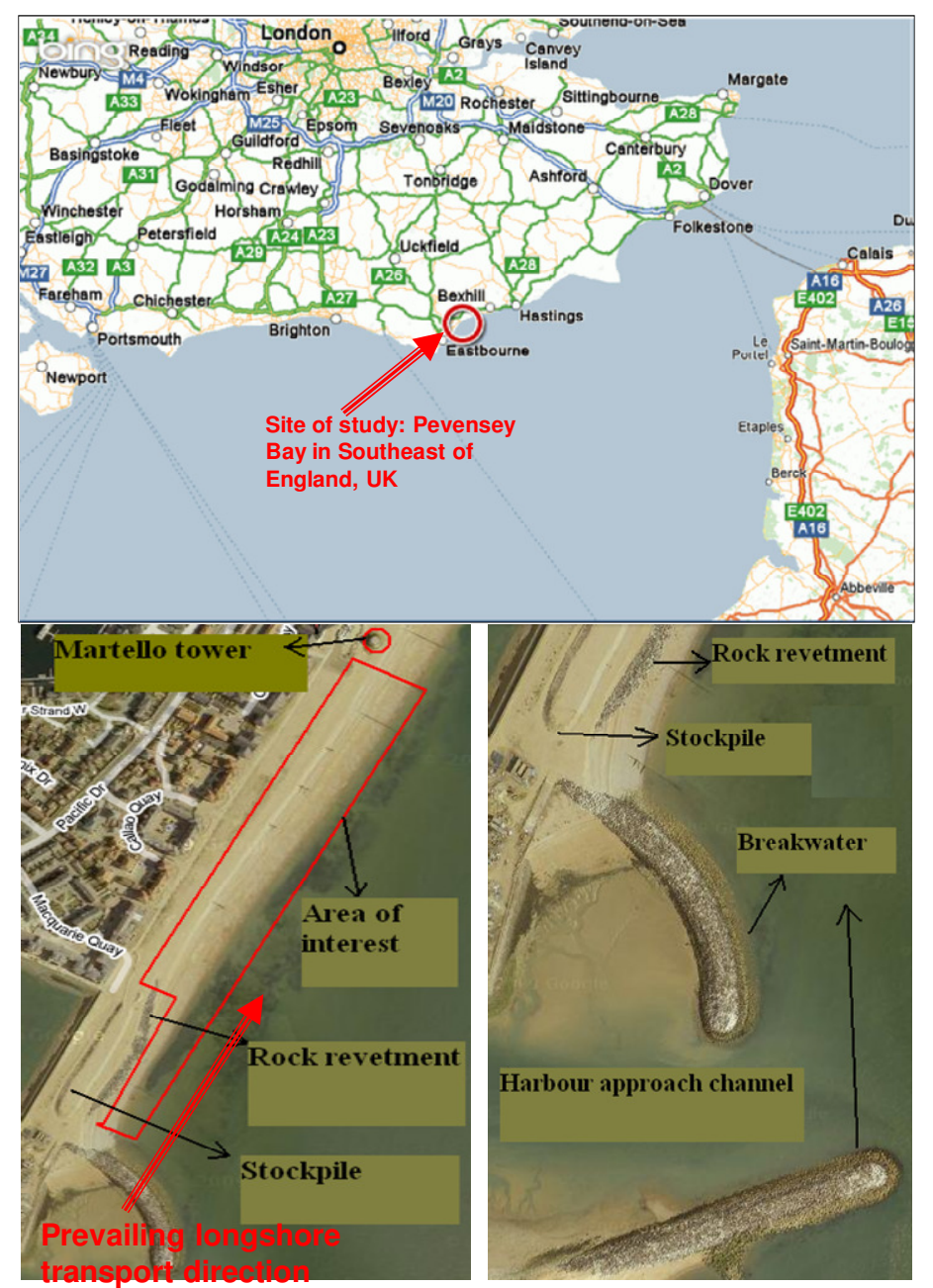

Figure 1. Location and area of interest

Figure 2 shows the locations at which the sediment samples were collected. The collection consists of two sets of five samples, with each set taken at five points along a line running in the crossshore direction. The five sampling points are placed at approximately $8 \mathrm{~m}$ intervals and these are intended to coincide with all major changes in morphology along the profile, such as mid-berm, mean high water, mid-tide, mean low water, and beach toe. Figure 3 shows the general beach profile and positioning of the sampling points.

The line position of the first set is approximately halfway along the frontage under study. The end of groyne GP07 is used as a local reference point and GP09 is used to position the second set. The collection of samples is made at the same positions so that the sediment characteristic changes over time may be followed.

As a maintained sea defence system, regular recycling and re-profiling take place, leading to continued disturbance to the beach sediment. However, because of the full extension of GP09 and GP10 all the way down to low water level, the $80 \mathrm{~m}$ section between these two groynes is generally undisturbed. This means that the sediment sorting in this section is allowed to take place without 
interference. Therefore, the first set of samples (1 5) represents the maintained section of the beach while the second set (6 10) provides a benchmark of a more natural evolving system. Clearly, this cannot represent a natural beach but a comparison between the two sets of samples still offers an opportunity to identify how the maintenance activities affects the sediment sorting process.

Past experience indicates that spatial variation is primarily in the cross-shore direction. Als such, the main effort of the sediment sampling exercise was to investigate the cross-shore behaviour while limited samples were taken in the longshore direction.

\section{Beach Crest}
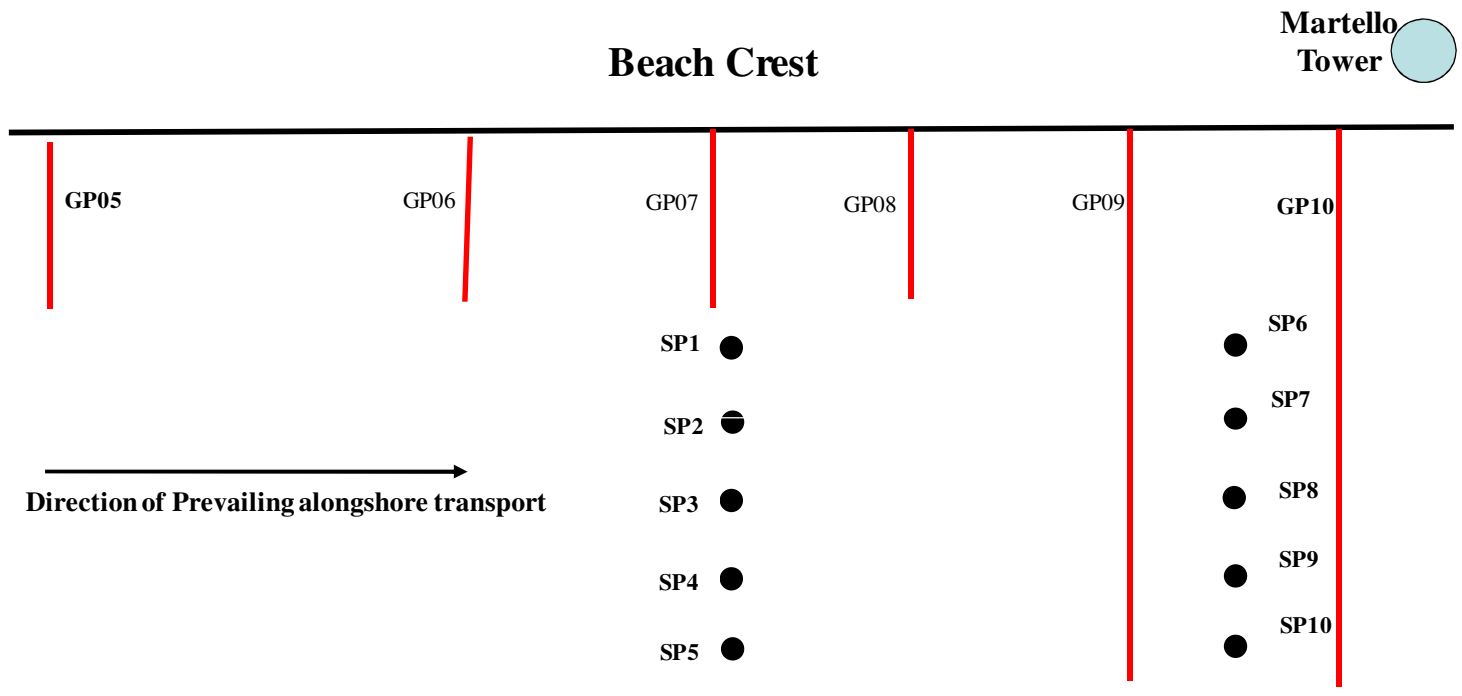

Figure 2. Positions of sediment sampling

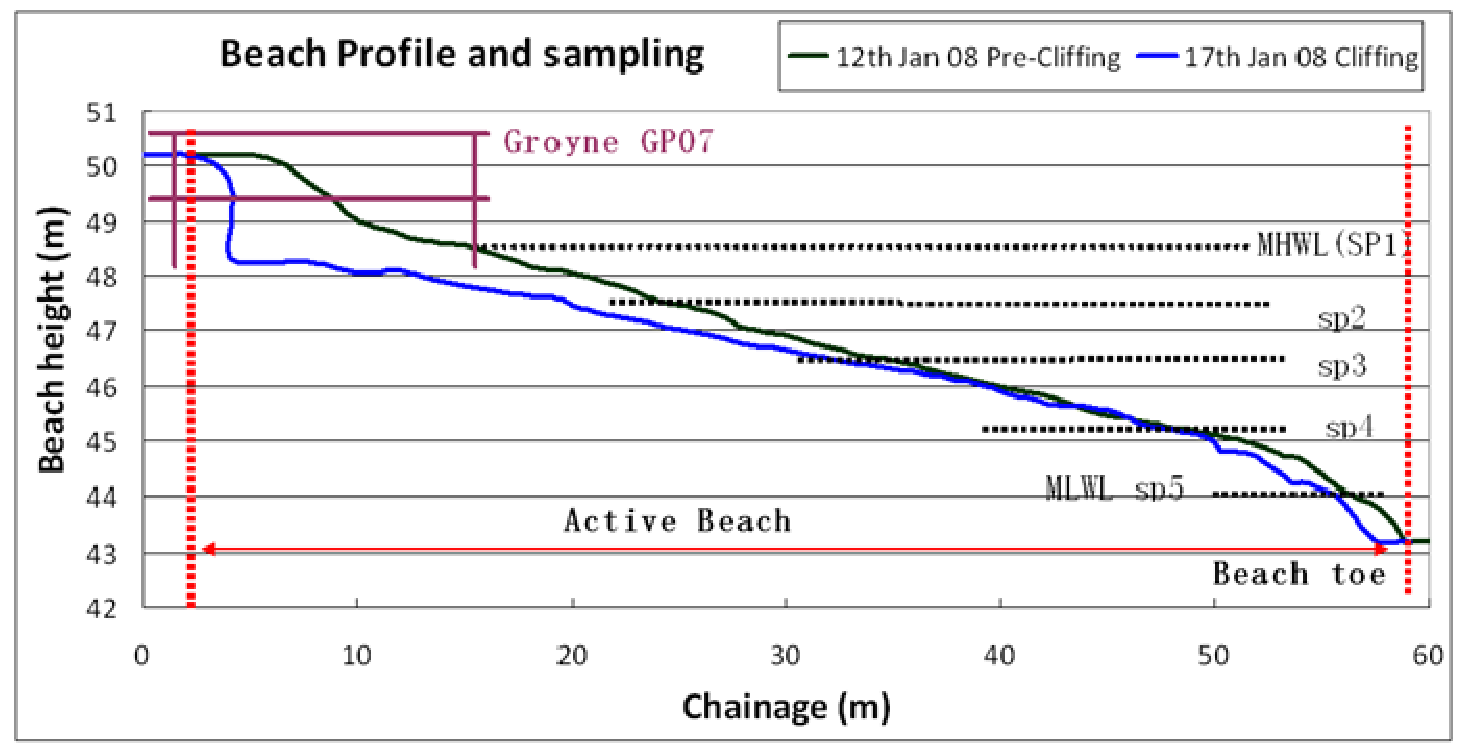

Figure 3. Sketch of cross-shore profile and relative positions of sediment sampling

Collection of sediment samples may be grouped into two categories as follows:

Regular sampling - carried out weekly in the month immediately after the annual recharge and reduced to monthly for the remainder of the year.

Events related sampling - collected just before and immediately after the beach material underwent significant changes due to maintenance activities, which include the main annual recharge, transfer of stockpile material onto the beach and local recycling. This group also includes one storm event. A list of major events is shown in Table 3.1.

Table 2 lists the number of collections and total number of samples taken under each category. The average weight of each sample is $8 \mathrm{~kg}$. 


\begin{tabular}{|c|c|c|c|}
\hline \multicolumn{4}{|c|}{ Table 1 Major events related sampling } \\
\hline \multirow{2}{*}{ Date } & \multirow{2}{*}{ Event } & \multicolumn{2}{|c|}{ Sampling dates } \\
\hline & & Before & After \\
\hline $\begin{array}{l}23^{\text {rd }}, 24^{\text {th }} \& 25^{\text {th }} \\
\text { July } 2007\end{array}$ & Recharge & $16^{\text {th }}$ Jul 07 & $\begin{array}{c}23^{\text {rd }}, \& 24^{\text {th }} 25^{\text {th }}, \& \\
30^{\text {th }} \text { Jul } 2007\end{array}$ \\
\hline $9^{\text {th }}$ Aug 2007 & Recharge & $\begin{array}{c}2^{\text {nd }} \& 6^{\text {th }} \text { Aug } \\
07\end{array}$ & $19^{\text {th }}$ Aug 07 \\
\hline $13^{\text {th }}$ Jan 2008 & Storm & $10^{\text {th }}$ Jan 08 & $27^{\text {th }}$ Jan 08 \\
\hline $4^{\text {th }}$ Oct 2008 & Recharge & $30^{\text {th }}$ Sep 08 & $\begin{array}{c}4^{\text {th }} \text { Oct } 08 \\
28^{\text {th }} \text { Oct } 08\end{array}$ \\
\hline
\end{tabular}

\begin{tabular}{|l|c|c|}
\hline \multicolumn{3}{|c|}{ Table 2 Summary of collected sediment samples } \\
\hline Category & Total collections & Total samples \\
\hline a) Regular & 20 & 195 \\
\hline b) Events related & 6 & 60 \\
\hline
\end{tabular}

\section{Basic descriptive parameters}

The sediment size is not a uniquely defined parameter but in coastal engineering applications the commonly adopted approach is to use sieve diameter to define the size of natural sediment such as sand and gravel. Sediments are generally characterised in terms of parameters such as mean grain diameter, median size and modal size, sorting (standard deviation) and so on. Differential sediment sizes within mixed gravel beaches is recognised as a dominating factor in mixed beach response, making them more complex than either sand or gravel beaches (Kirk, 1980). These beaches demonstrate radically different processes involved in cross-shore and longshore transport driving the need for independent research and predictive capabilities.

Sediments on mixed sand and gravel beach can have sizes ranging over three orders of magnitude, from fine sands to boulders. The boundaries between classes can be expressed either in millimetres or phi units $(\Phi)$. The phi transformation recognises the logarithmic equality of the scale divisions. Sediment size in phi units is calculated from the size in millimetres, defined as:

$$
\Phi=-\log _{2} \mathrm{D}
$$

Where D is grain size in mm. $\Phi$ values decrease with increasing particle size.

The standard deviation is a measure of the degree to which the sample spreads out around the mean. Following Folk (1974), the standard deviation can be approximated by:

$$
\sigma_{\Phi}=\frac{\Phi_{84}-\Phi_{16}}{4}+\frac{\Phi_{95}-\Phi_{5}}{6}
$$

Note that $\sigma_{\Phi}$ is the estimated standard deviation of the samples in phi unit, and $\Phi_{5}, \Phi_{16}, \Phi_{84}, \Phi_{95}$ are the percentiles corresponding to 5,16,84 and 95\%, respectively. If the particle sizes are distributed evenly over a wide range of sizes, then the sample is said to be poorly sorted. If the sediment is completely well sorted or poorly mixed, then $\sigma_{\Phi}=0$. Folk (1974) describes the sediment sorting quantitatively in terms of the standard deviation as demonstrated in Table 3 below: 


\begin{tabular}{|l|l|}
\hline \multicolumn{2}{|c|}{ Table 3 Description of sediment sorting in terms of the standard deviation } \\
\hline$\Phi$ Range & Description \\
\hline$<0.35$ & Very well sorted \\
\hline $0.35-0.50$ & Well sorted \\
\hline $0.51-0.70$ & Moderately well sorted \\
\hline $0.71-1.00$ & Moderately sorted \\
\hline $1.00-2.00$ & Poorly sorted \\
\hline $2.00-4.00$ & Very pool sorted \\
\hline$>4.00$ & Extremely pool sorted \\
\hline
\end{tabular}

\section{RESULTS AND DISCUSSIONS}

\section{Sediment size distribution}

It is well accepted fact that mixed beaches is normally characterised by a bimodal sediment distribution, with one mode in the sand fraction and another in the gravel fraction. Characterising a bimodal sediment quantitatively is difficult, as the use of standard parameters (such as mean, median) can produce results which have no significance in a physical sense. The bimodality of the sediment also appears to affect fine fractions more than coarse fractions (Wilcock, 1993). Wilcock et al. (2001) showed that adding sand to the bulk mixture clearly increased the transport rate of the gravel portion of the bed as well as the total transport rate. When two modes are present, the median or mean may fall in the gap between modes and may therefore represent a size fraction with little or no sediment.

In past studies, the bimodality has been shown by way of plotting the percentage of sediment retention against sieve sizes. While the method serves its purpose well but it tends to bias towards the larger grain sizes. This is because the standard sieve sizes follow a logarithmic distribution and the difference between two successive sieve sizes increases with the size of the sieves. To avoid this problem, we propose a new parameter as follows:

$$
\mathrm{R}_{\mathrm{D}}=\frac{\mathrm{PR}}{\log _{2}(\mathrm{SD} 2)-\log _{2}(\mathrm{SD} 1)}
$$

where SD1 and SD2 are the sizes of two successive sieves in the sieve analysis and PR is the percentage of sediment retained between the two sizes. RD is referred to as the sediment retention density at the grain size $\mathrm{D}=(\mathrm{SD} 1+\mathrm{SD} 2) / 2$. It may also be said to be the percentage retention per unit $\Phi$. This is because $\log _{2} \mathrm{D}=-\Phi$. The sediment retention density is a reflection of the relative amount of sediment at a given sediment size in a mixed sediment.

Figures $4 \& 5$ are typical examples from samples collected in this study. Bimodality is beyond any doubt a general characteristics of the sediment on the Pevensey frontage. Note that samples SP1 SP5 are taken at 5 different points across the beach from mean high water level down to mean low water level, thus reflecting the sediment size variation in the cross-shore direction. Samples 6 10 are taken parallel with SP1 SP5 but further down the shoreline where the beach surface is generally left alone, which is in contrast to the maintenance activities affecting SP1 SP5. It is interesting to note that the bimodal characteristics is equally strong at both longshore locations despite significant disturbances at SP1 SP5 due to maintenance work. The peak value, however, can vary significantly between the samples points. In general, the peak value corresponding to the gravel fraction is highest at SP1/SP6, which is the closest to the beach crest. The differences between the lower points are less definable. Samples at SP1/SP6 may or may not contain sand fractions while the other points all have sand. The peak values do not show any consistent behaviour between these points in a spatial sense. A more systematic method is needed and will be discussed further down the chapter in order to underpin any possible trend in the spatial and time dependent behaviour of the sediment distribution.

In the above discussion, sand fraction refers to grain size less or equal to $1 \mathrm{~mm}$ and gravel fraction indicates grain size above $1 \mathrm{~mm}$. 


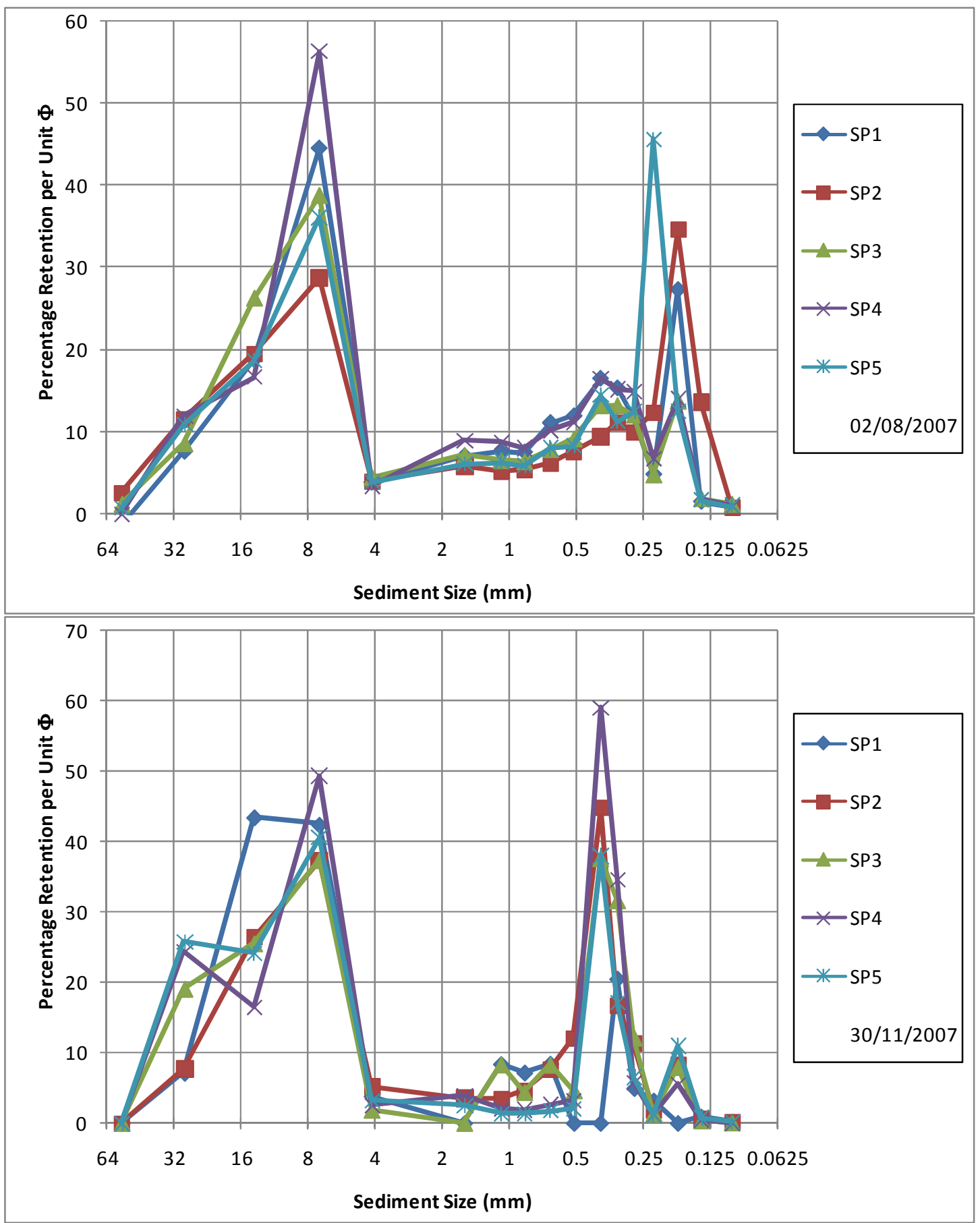

Figure 4. Bi-modal sediment size distributions from disturbed site at Pevensey Bay 

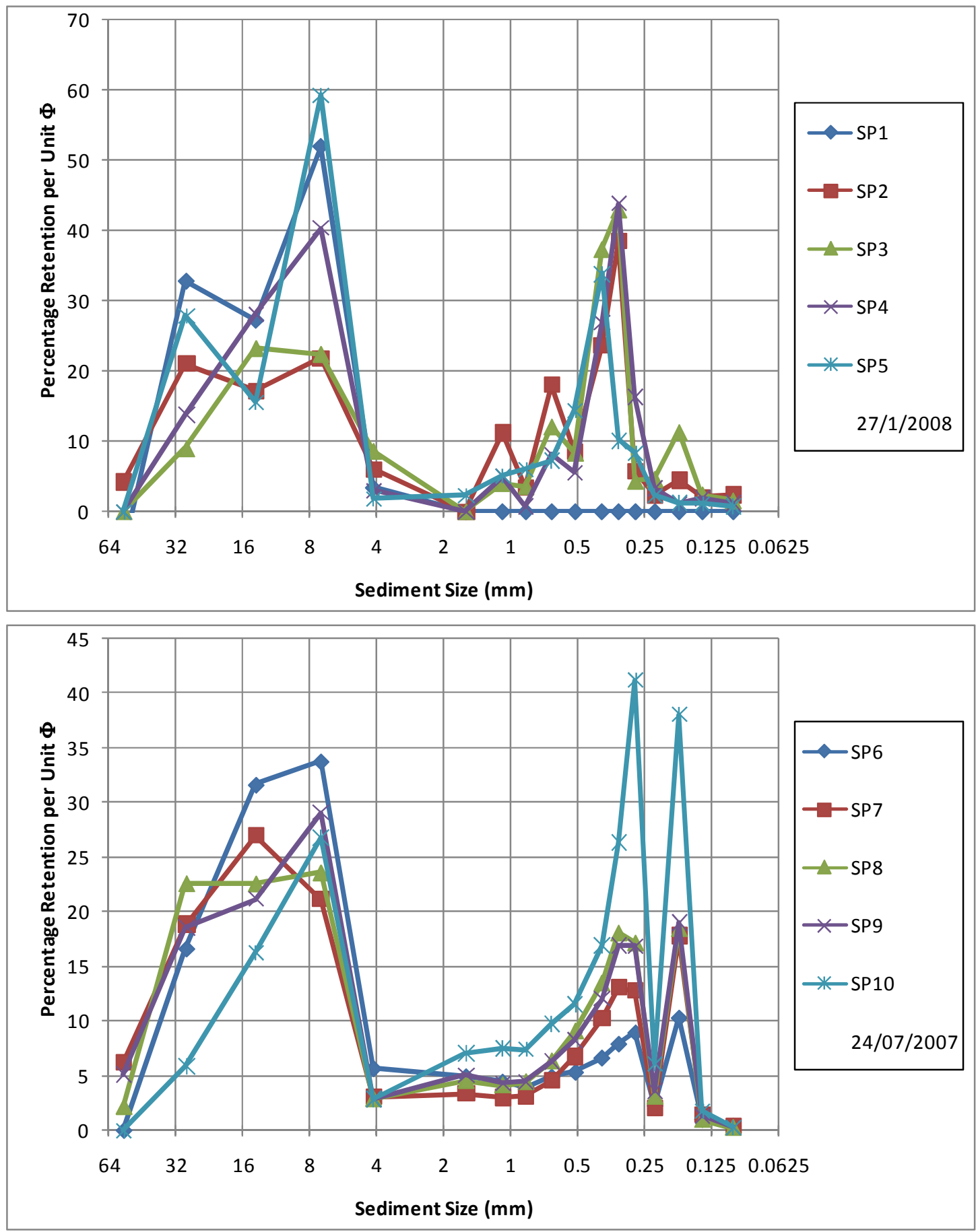

Figure 5. Bi-modal sediment size distributions from natural site at Pevensey Bay

\section{Characteristic sediment sizes}

As indicated earlier, plotting the sediment distribution in the form of the retention density against sediment size does not real any systematic behaviour across the beach surface in the cross-shore direction. To explore the possibility of any underlying trend both spatially and over time, we will first look at the basic descriptive parameters as described earlier.

Representation of a mixed sediment is conventionally by means of the $\mathrm{D}_{50}$ together with $\mathrm{D}_{5}, \mathrm{D}_{16}$, $D_{84}$, and $D_{95}$. $D_{84}$ and $D_{95}$ serve a similar purpose, that is to show the coarse component of the sediment. Figures $6 \& 7$ show $\mathrm{D}_{84}$ for the duration of a full year cycle between two annual recharges. There is a fluctuation over the year but it is not clear what the underlying pattern is. In terms of the 
cross-shore variation, the top of the beach (SP1/SP6) seems to contain coarser material than lower down the beach. The differences between the other points are however, far from obvious.

In a similar way, $\mathrm{D}_{5}$ and $\mathrm{D}_{16}$ may be used to identify if fine material is contained in the sediment. Figures 8 \& 9 show $\mathrm{D}_{16}$ for the twelve month period starting from July 2007. There is again a clear difference between the top of the beach (SP1/SP6) and the remaining positions across the beach. More fine material is contained in the lower down the beach.

In theory, $\mathrm{D}_{50}$ is the single most important parameter in the definition of a sediment mix, as it is used in almost all engineering applications as the key design parameter. Yet it is widely recognised that $\mathrm{D}_{50}$ is not an effective representation of a mixed sediment with a bimodal character. This problem may be highlighted by looking at its spatial variation and over time in the present investigation (Figures 10 \& 11). Apart from the top of the beach (SP1/SP6) where the sediment is almost free from sand material, the $\mathrm{D}_{50}$ values show very large fluctuations in a random manner both across the beach and over time. It is clear that a more representative parameter is needed for sediment of a bimodal nature and further discussions will be given later.

\section{Sediment sorting}

Discussions about mixed beaches are incomplete without looking at the sediment sorting. The sediment sorting is quantified by the use of equation 2, which approximates the standard deviation of the sediment size distribution. The smaller the value, the better sorted the sediment. A sediment mix with a value greater than 4 is deemed extremely poorly sorted. Figure $12 \& 13$ show the sorting parameter against time. All samples with one exception show a value greater than 4. As in the case of $\mathrm{D}_{16}, \mathrm{D}_{50}$, and $\mathrm{D}_{86}$, no pattern or trend can be identified in a spatial sense or in time. For a mixed beach with bi-modal characteristics, the standard deviation is just another parameter of confusion.

\section{Median size of gravel and sand fractions}

It is clear that no underlying behavior can be identified by means of conventional characteristic sizes such as $\mathrm{D}_{50}$. What seems clear is that the beach sediment is strongly bimodal. It should be possible to look at the sand and gravel fractions of the sediment separately. The cut-off point between sand and gravel is somewhat arbitrary and a value of $1 \mathrm{~mm}$ is used here. Sediment passing a $1 \mathrm{~mm}$ sieve is regarded as sand. Once the two fractions are separated, the median sizes of both fractions can be worked out. Figures 14 17 show these sizes for the duration of the one year period. The median gravel size $\mathrm{D}_{50 \mathrm{~g}}$ does not seem to vary much in the cross-shore direction. The variation over time is also very small. The same can be said about the median sand size $D_{50 s}$ except that there is a more distinctive increase in size immediately after the annual beach recharge in July/August. The trend of increase in $\mathrm{D}_{50 \text { s }}$ over time is evident from both sets of samples. It is possible that the finest fraction of the sand becomes washed away soon after the recharge took place.

It is now evident that the basic characteristics of both the coarse and fine fractions of the sediment remained reasonably stable. This leaves the apparent coarsening or fining effects seen on the beach with only one possible explanation, the proportions of the two fractions. Figure $18 \& 19$ shows the percentage of sand over the 12 month recharge cycle. It can be seen that sand percentages across the beach are relatively high throughout the cross-shore direction. The percentages at each point show a fluctuation with time. As the samples were collected at fixed positions, the sediment content is likely influenced by the tidal cycle. This is the most obvious at SP1/SP6. If the high water level is sufficiently above this point, the sediment sorting process brings in sand so that the sediment composition becomes more like SP2/SP7. If the high water level is at or below the top sampling point, we then have no sand in the sample.

\section{CONCLUDING REMARKS}

The sediment characteristics of a mixed beach sediment is examined with respect to space and time. The influence of the beach management on the sediment characteristics is also looked at. Main conclusions from the analysis are as follows:

- The sediment shows a distinctive bi-modal characteristics. A new characteristic parameter is introduced, referred to as the retention density of the sediment distribution. The new parameter ensures that the distribution of the sediment sizes is truly reflected rather than a bias towards the coarse fraction of the sediment mix.

- Conventional presentation of the sediment in terms of median size $\mathrm{D}_{50}$ together with $\mathrm{D}_{95}, \mathrm{D}_{84}, \mathrm{D}_{16}$, and $\mathrm{D}_{5}$ was shown to be grossly insufficient in the characterisation of a mixed sediment of a bimodal nature. The sorting parameter (standard deviation of the sediment sizes) is unable to 
provide any definable behaviour apart from the well known fact that the sediment on a mixed beach is always extremely poor sorted irrespective of the location and time.

- Analysis of the median sizes of the gravel and sand fractions indicates that the fundamental characteristics of the sediment remains reasonably stable both spatially and in time. The apparent changes in the sediment in space and time are more to do with the tidal influence, which causes the percentage of the sand to vary significantly both spatially and temporally.

- Apart from the period immediately after the annual recharge when the sediment seems to undergo a significant natural sorting process, minor maintenance activities such as local recycling do not seem to have a significant impact on the fundament sediment characteristics.

- For engineering applications involving mixed sediment, the use of conventional median sized $\mathrm{D}_{50}$ should be avoided. It is necessary to investigate the possibility of an alternative sediment size based on the median sizes of the sand and gravel fractions of the sediment.

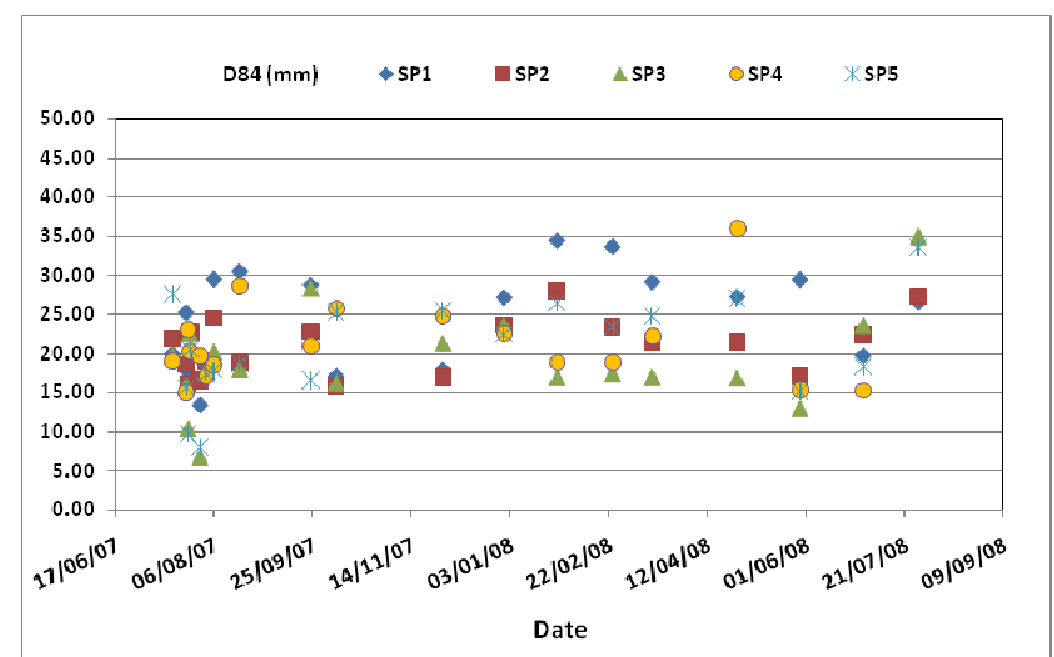

Figure 6. $\mathrm{D}_{84}$ versus dates (SP1 SP5)

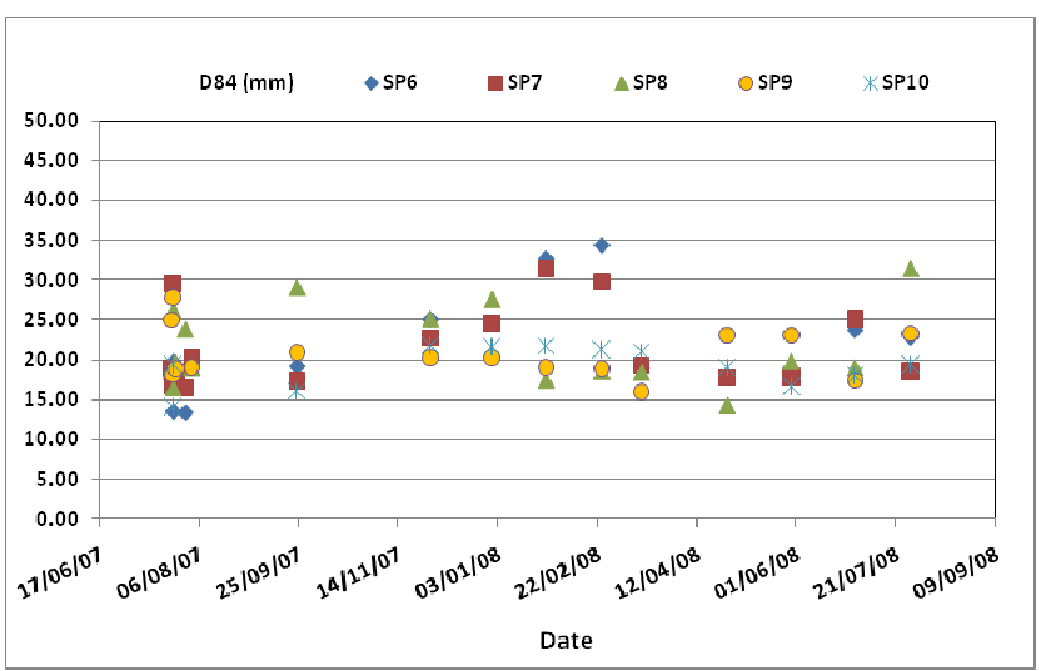

Figure 7. $D_{84}$ versus dates (SP6 SP10) 


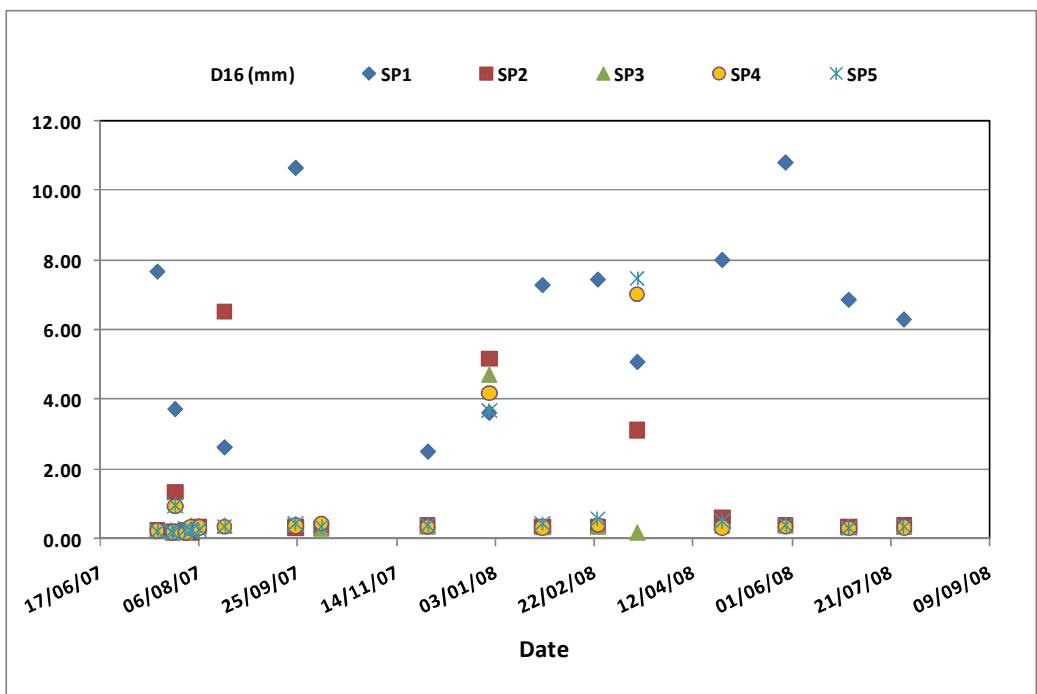

Figure 8. $\mathrm{D}_{16}$ versus dates (SP1 SP5)

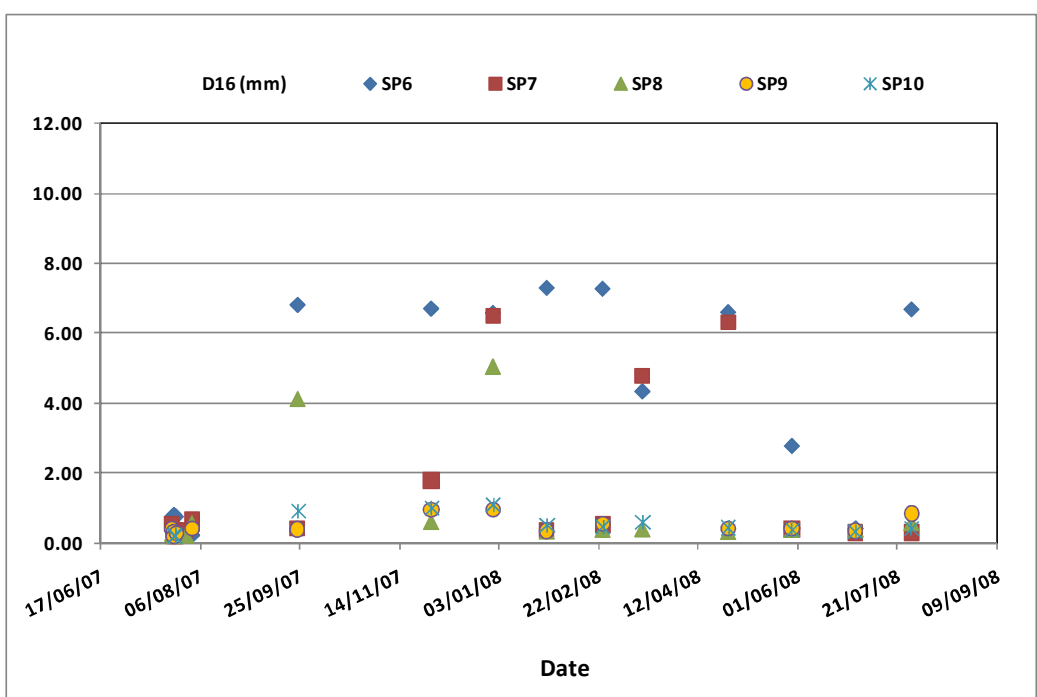

Figure 9. $D_{16}$ versus dates (SP6 SP10)

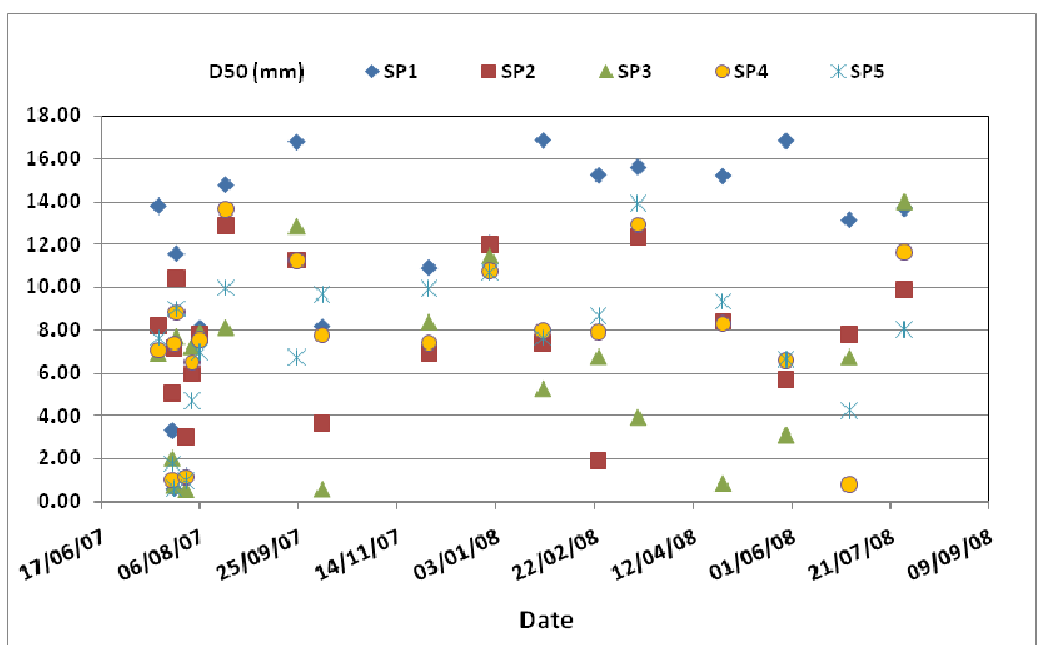

Figure 10. $\mathrm{D}_{50}$ versus dates (SP1 SP5) 


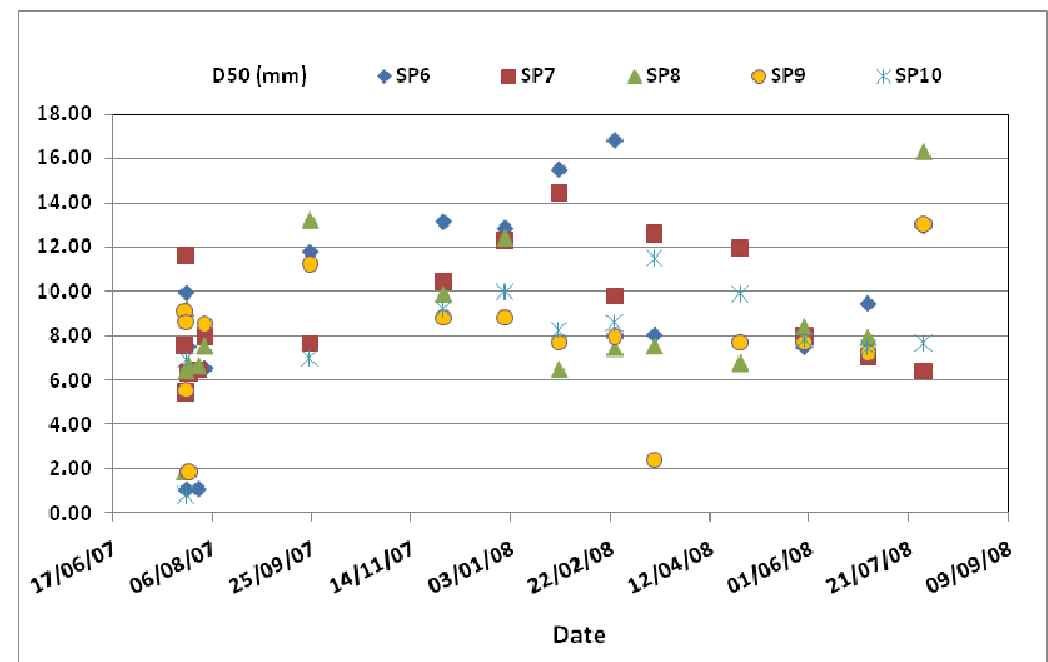

Figure 11. $D_{50}$ versus dates (SP6 SP10)

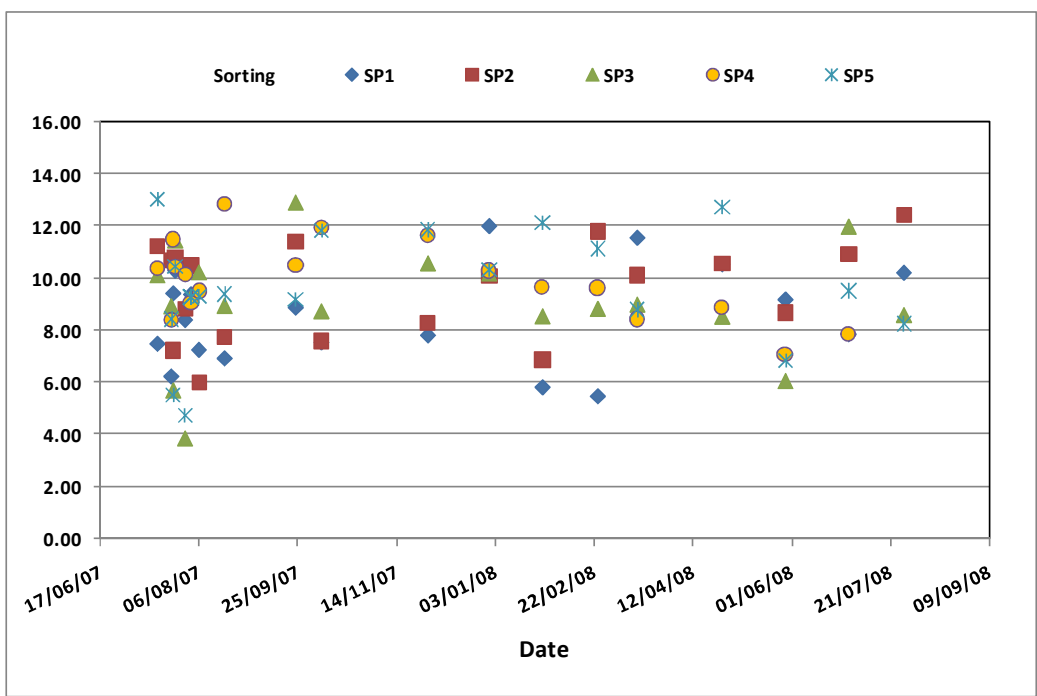

Figure 12. $\sigma_{\Phi}$ versus time (SP1 SP5)

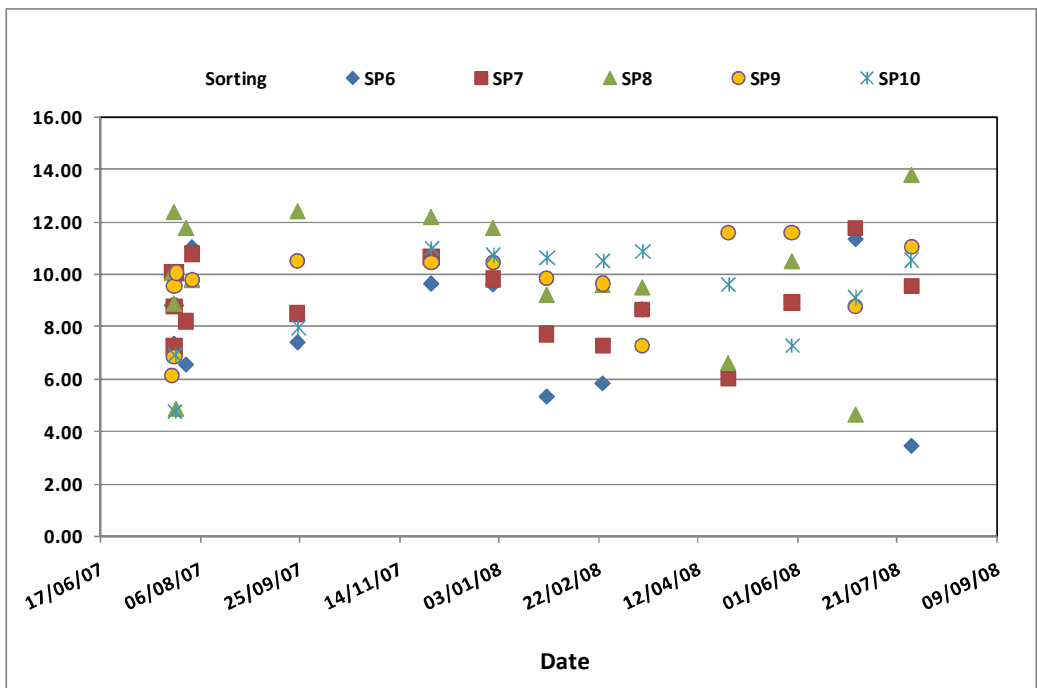

Figure 13. $\sigma_{\Phi}$ versus time (SP6 SP10) 
11

COASTAL ENGINEERING 2010

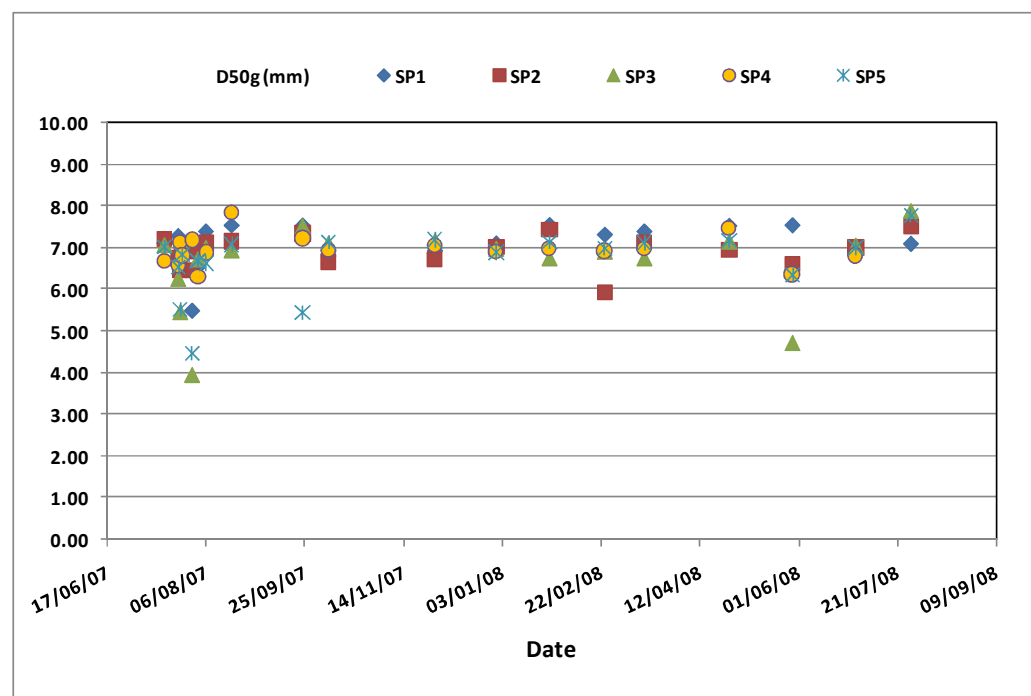

Figure 14. $D_{50 g}$ versus dates (SP1 SP5)

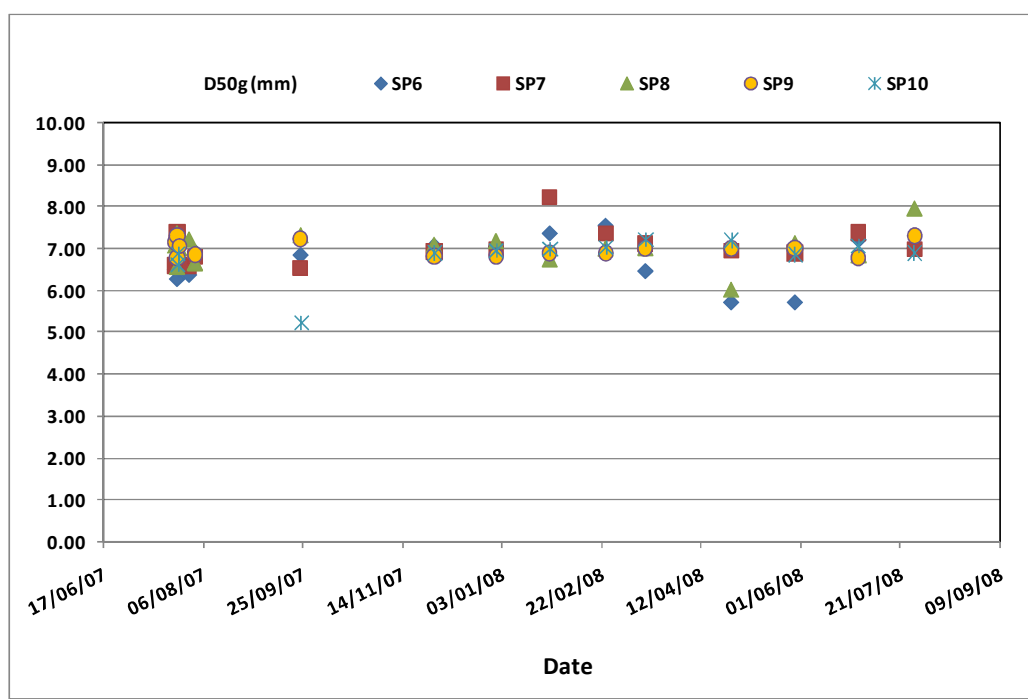

Figure 15. $D_{50 g}$ versus dates (SP6 SP10)

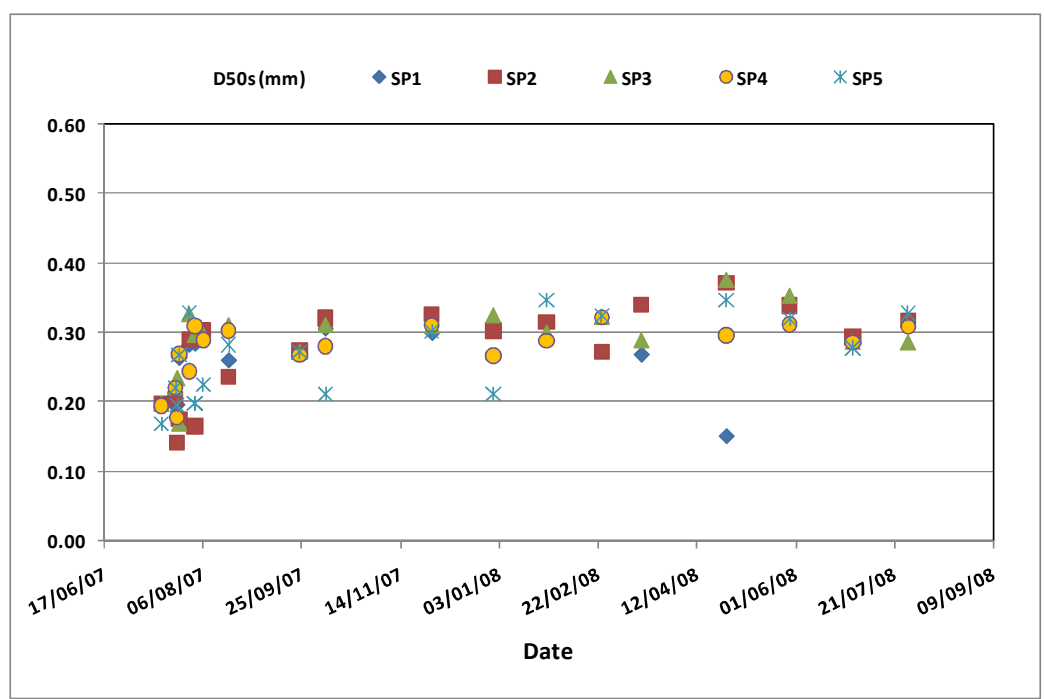

Figure 16. $D_{50 s}$ versus dates (SP1 SP5) 


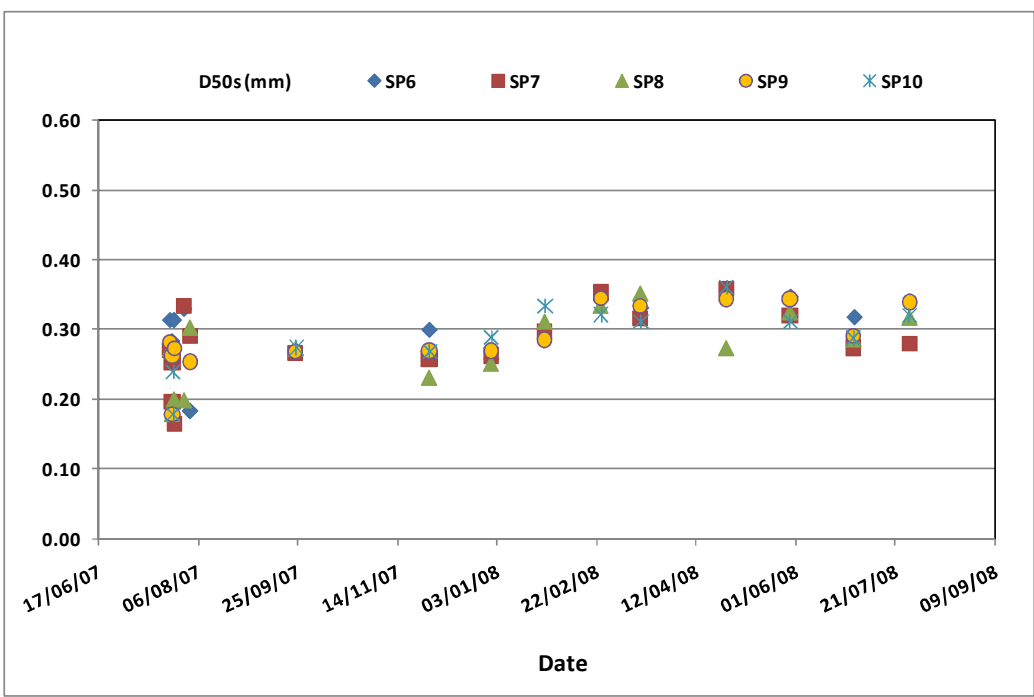

Figure 17. $D_{50 s}$ versus dates (SP6 SP10)

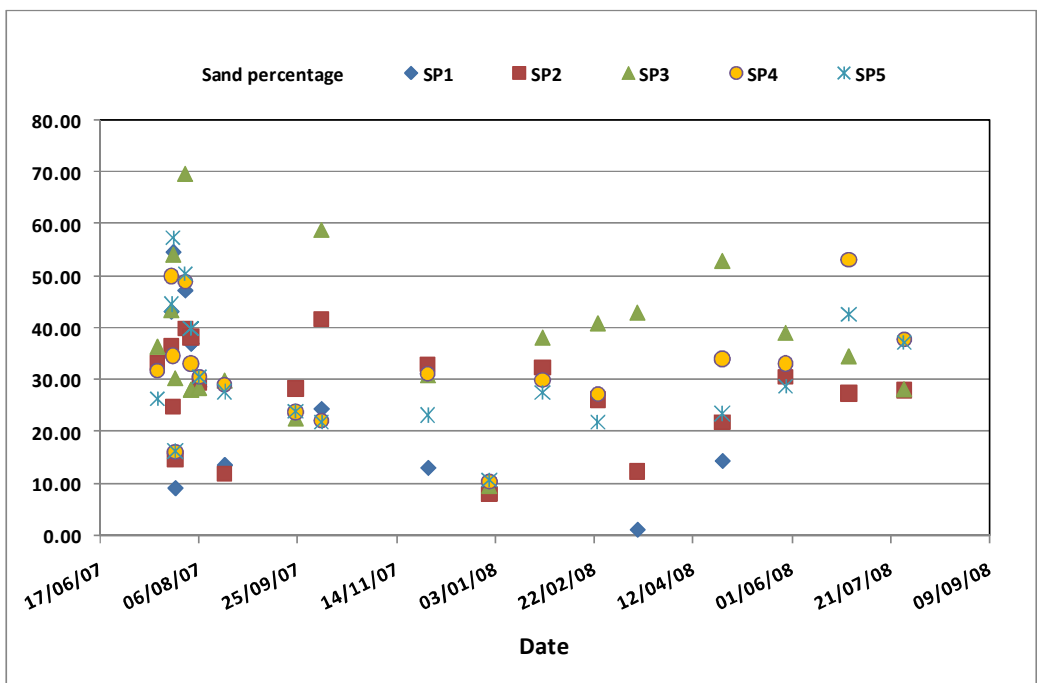

Figure 18. Variation of sand percentages over time (SP1 SP6)

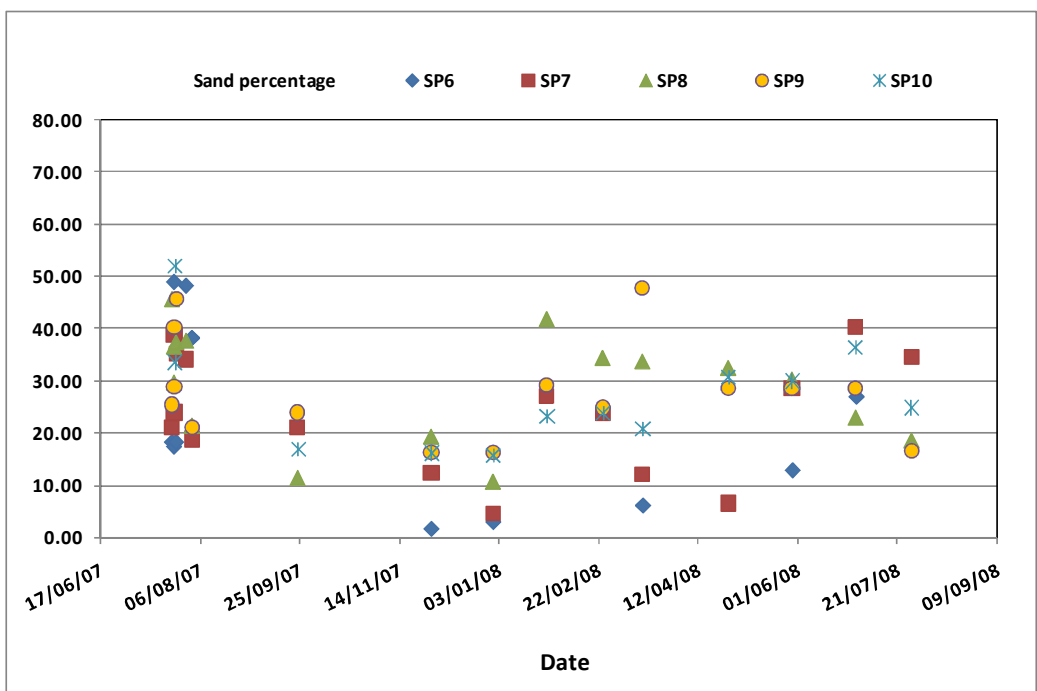

Figure 19. Variation of sand percentages over time (SP6 SP10) 


\section{REFERENCES}

British Standards Institution. 1990. Methods of test for soils for civil engineering purposes. BS1377. London: British Standards Institution.

Folk, R. L. 1974. Petrology of Sedimentary Rock, Hemphill Publishing Company, Austin, TX. pp 48.

Kirk, R.M. 1980. Mixed sand and gravel beaches: morphology, processes and sediments. Progress in Physical Geography 4: pp 189-210.

Powell, K.A. 1990. Predicting short term profile response for shingle beaches. HR Wallingford SR report 628.

Wilcock, P.R. and McArdle, B.W. 1993. Surface-based fractional transport rates: mobilization thresholds and partial transport of a sand-gravel sediment. Water Resources Research 29(4): pp 1297-1312.

Wilcock, P.R., Kenworthy, S.T., and Crowe, J.C., 2001, Experimental study of the transport of mixed sand and gravel, Water Resources Research 37 (12) (2001), pp. 3349-3358. 